\title{
Use of Lignin-Derived Carbon to Prepare Nickel-Based Electrocatalysts for Water Splitting
}

\author{
Jia Hui ${ }^{1}$, Meng Xiang ${ }^{2}$, Jianxiang Chen ${ }^{2}$, Shilong Zhou ${ }^{2}$, Yin Cheng ${ }^{1, *}$ and Zhou Yang ${ }^{2, *}$ \\ ${ }^{1}$ Engineering Technology and Materials Research Center, China Academy of Transportation Sciences, \\ Beijing 100029, China \\ ${ }^{2}$ Department of Material Engineering, Jiangsu University of Technology, Changzhou 213001, China \\ "E-mail: by0913108@buaa.edu.cn, zhouyang@jsut.edu.cn
}

doi: $10.20964 / 2021.03 .57$

Received: 18 November 2020 / Accepted: 8 January 2021 / Published: 31 January 2021

\begin{abstract}
Water splitting is the most feasible way of obtaining hydrogen energy, but the high overpotential of the electrocatalytic materials conventionally used for water splitting create a bottleneck in the process. Herein, we prepare a $\mathrm{NiS}_{\mathrm{x}} / \mathrm{C}-780$ electrocatalyst derived from lignin and nickel that exhibits good electrocatalytic properties and for which the overpotential of $358 \mathrm{mV}$ at $10 \mathrm{~mA} \mathrm{~cm} \mathrm{~cm}^{-2}$ for the oxygen evolution reaction (OER) and the Tafel slope of $107.7 \mathrm{mV} \mathrm{dec}^{-1}$ are superior to those of commercial $\mathrm{RuO}_{2}$. This study serves as a reference for designing low-cost and environmentally friendly electrocatalysts for water splitting.
\end{abstract}

Keywords: lignin, water splitting, nickel, electrocatalyst

\section{FULL TEXT}

(C) 2021 The Authors. Published by ESG (www.electrochemsci.org). This article is an open access article distributed under the terms and conditions of the Creative Commons Attribution license (http://creativecommons.org/licenses/by/4.0/). 